\title{
A Theoretical Integration of Schema Therapy and Cognitive Therapy in OCD Treatment: Conceptualization and Rationale (Part II)
}

\author{
Katia Tenore $^{1 *}$, Barbara Basile1, Francesco Mancini ${ }^{1,2}$, Olga Ines Luppino ${ }^{1,2}$ \\ ${ }^{1}$ Association of Cognitive Psychology, School of Cognitive Psychotherapy, Rome, Italy \\ ${ }^{2}$ Marconi University, Rome, Italy \\ Email: *tenore@apc.it
}

How to cite this paper: Tenore, K., Basile, B., Mancini, F., \& Luppino, O. I. (2018). A Theoretical Integration of Schema Therapy and Cognitive Therapy in OCD Treatment: Conceptualization and Rationale (Part II). Psychology, 9, 2278-2295.

https://doi.org/10.4236/psych.2018.99130

Received: July 2, 2018

Accepted: September 8, 2018

Published: September 11, 2018

Copyright ( $) 2018$ by authors and Scientific Research Publishing Inc. This work is licensed under the Creative Commons Attribution International License (CC BY 4.0).

http://creativecommons.org/licenses/by/4.0/

\begin{abstract}
Cognitive Behavioral Therapy has been identified as the first choice treatment for Obsessive Compulsive Disorder (OCD). Although a significant proportion of patients benefit from Cognitive Behavioral Therapy, another still fails to respond to CBT. To improve outcomes, new targets of intervention have been broadened, but no clear and comprehensive conceptualizations of the disorder have been suggested. In the last few years, in the context of Schema Therapy (ST), several specific models have been proposed for the treatment of Axis I diagnostic categories (according to the classification of DSM IV), in addition to the more well-known conceptualizations related to Personality Disorders. Concerning OCD, several studies have investigated the effectiveness of ST in the treatment of OCD, but only few have tried to elaborate a conceptualization of the disorder in terms of modes. This lack of knowledge and shared conceptualization might lead to difficulties in planning and evaluating effective interventions. The aim of this work is to present a conceptualization of the Obsessive Compulsive Disorder that results from the integration between the Cognitive Therapy framework, as proposed by Mancini and collaborators, and the framing in terms of modes, in line with ST, starting from the research data available. In particular, the rationale of the intervention will be proposed, aimed at accepting the risk of committing mistakes or of coming into contact with disgusting substances. This general aim will then be articulated in sub-aims, which may direct it, in a more specific way, on the basis of the different modes that characterize the experience of obsessive patients.
\end{abstract}

\section{Keywords}

Obsessive-Compulsive Disorder, Schema Therapy, Cognitive Therapy, Acceptance, 
Mode Work, Rationale of Intervention

\section{Introduction}

Cognitive Behavioral Therapy has been identified as the first choice treatment for Obsessive Compulsive Disorder (OCD). Although, a significant proportion of patients benefit from Cognitive Behavioral Therapy (CBT), another still fails to respond to CBT (Abramowitz, Franklin, Schwartz, \& Furr, 2003; Rufer, Fricke, Moritz, Kloss, \& Hand, 2006; Tolin, Maltby, Diefenbach, Hannan, \& Worhunsky, 2004). To improve outcomes new targets of intervention have been suggested (Veale et al., 2015), but no clear and comprehensive conceptualizations of the disorder have been proposed. As shown by Luppino (Luppino et al., 2018), sensitivity to deontological guilt and disgust constitutes the proximal psychological determinants of OCD, implied in the genesis and maintenance of the disorder. Deontological guilt (Mancini \& Gangemi, 2004) and disgust render a person more prone to develop OCD, and these sensitivities reflect the core and pervasive life themes, which, if not addressed, may make relapses more likely to occur. At the best of our knowledge only few studies have addressed these sensitivities directly (Consentino et al., 2012; Cosentino \& Mancini, 2012; Perdighe \& Mancini, 2012; Vos et al., 2012; Tenore et al., 2018), which are high in OCD patients, also in the non-symptomatic domains. ST may help in fulfilling the lack of therapeutic tools aimed at addressing the historical vulnerability factors implied in OCD.

ST was developed by Young in the 1990s, as a structured theoretical approach that integrates cognitive behavioral therapy (CBT) with different theoretical models such as attachment theory, transactional analysis, psychoanalysis, and Gestalt theory (Young et al., 2003). Its main therapeutic objective is to identify the frustrated core needs of patients, to satisfy them through functional strategies. According to ST, frustration of core emotional needs in early childhood and adolescence leads to the development of Early Maladaptive Schemas, i.e. pervasive themes or patterns that develop early and that consist of memories, somatic sensations, emotions and cognitions about oneself and relationships. The concept of schema well describes those conditions of vulnerability in patients that make them more susceptible to developing a certain disorder. These are ideas and expectations about oneself and others, which derive from the interaction between interpersonal experiences of frustration of primary emotional needs and temperamental predispositions. In the definition of Schema there are several historical connotations. One is the component of memories, organized in a network, that share the experiences of activation of the schema. The other is constituted by the conditions of frustration of primary needs, which gives rise to the schema itself. Both represent the patients' historical vulnerability, which in the case of obsessive patients has certain specific traits (see Luppino et al., 2018) 
and which motivates the obsessive activity. As described by Luppino et al. (2018) these experiences lead to a sensitization to the themes of guilt, in particular deontological, and of disgust.

The behavioral pattern is not present in the definition of Schema. When one or more schemas are activated, some important goal for the patient is threatened and consequently the Coping responses are activated. These consist in the typical responses of fight, flight and freeze, used by the child during childhood, aimed at guaranteeing survival in a frustrating environment. Following the concept of Schema, ST authors introduced the concept of mode. If a Schema represents a trait, a stable characteristic of a person, a mode represents its activation, which is contingent, occurring at a particular moment. A mode consists of emotional states, patterns and coping reactions that are activated in a given situation. The transition from one mode to another is a common experience; each of us experiences the transition from one state to another state over time, while maintaining a continuity in the sense of self. What determines individual differences is the prevalence of a particular mode over others and the rapidity with which the transition from one mode to another takes place (Tenore \& Serrani, 2013). Modes can refer to 1) parts that express needs and emotions, called Child mode (e.g. alone, vulnerable, sad, abused, furious), 2) parts that represent introjected parental voices, called Parent mode (e.g. demanding, critical, punitive), 3) parts that represent specific coping responses defined as Coping modes, they include Surrender mode (unassertive, submissive in relationships), the Avoidance mode (isolation, dissociation, social and behavioral avoidance) and Attack/Overcompensator mode (critical, judging, violent). Therefore, modes represent a more dynamic way, compared to schemas, to describe the intrapsychic dynamics of patients. This form of conceptualization proves to be particularly useful in describing the functioning of obsessive patients. As can be seen in Mancini and collaborators' internal profile of the functioning of the disorder (Mancini, 2018; Luppino et al., 2018), the obsessive patient goes through different mental states, characterized by different emotional experiences, which will be described further on in this paper.

Although Schema Therapy was developed to treat personality disorders, it has over time proved to be useful in the intervention on all those pathological personality traits that, under the Axis I symptomatology, often represent important maintenance factors, reducing considerably the potential effectiveness of traditional CBT. It is not infrequent, in fact, that a cognitive-behavioral therapy is undertaken to deal with an Axis I disorder but that, having obtained a reduction of the acute symptomatology, patients find themselves dealing with some dysfunctional personality trait.

In recent years, specific models have been proposed for the treatment of Depression (Renner et al., 2013), of Borderline Personality Disorder (Kellogg \& Young, 2006), of Narcissistic Personality Disorder (Behary, 2009), of Personality Disorders of Cluster C (Arntz, 2012) as well as other diagnostic categories. Con- 
cerning the Obsessive Compulsive Disorder-the core interest of the present work-several studies have investigated the effectiveness of ST or of some of its techniques, in the treatment of OCD (Veale et al., 2015; Thiel et al., 2016), but only few have attempted to develop a conceptualization of the disorder in terms of modes. The lack of a shared conceptualization, based on clinical observation and research evidence, represents a weak point in the planning of an effective intervention and in the evaluation of the latter.

Gross and collaborators (2012), with a work on two single cases, have proposed a specific formulation in terms of modes, suggesting that ST may be particularly useful in the treatment of severe or chronic OCD, in cases of non-responders to traditional CBT and for those patients with a traumatic history or co-morbidity with Personality Disorders. More recently, Basile and colleagues (2017) have investigated Schema, modes and coping styles prevalent in a group of obsessive patients, providing interesting suggestions in light of a broader understanding of the disorder in terms of etiology and symptomatic maintenance. In line with the suggestions put forward by the authors just mentioned, the aim of this work is to present a conceptualization of Obsessive Compulsive Disorder that derives from the integration of Cognitive Therapy, as proposed by Mancini (2018), and ST, in terms of modes. This conceptualization aims not only to serve as a starting point for a theoretical reflection, but also to be the first step of an attempt to concretely apply the main techniques of ST to the treatment of OCD. Specifically, we intend to explain the obsessive functioning in order to more easily formulate the case and the planning of the therapeutic intervention.

\section{OCD and ST}

After clarifying the conceptualization of Obsessive Compulsive Disorder within the theoretical framework of cognitive therapy, we will now trace an overview of the main literature on diagnostic classification and on the functioning of the disorder from the point of view of ST. A contribution by Voderholzer and colleagues (2014) investigated early maladaptive patterns, modes and traumatic experiences in patients with OCD, comparing them to patients with other Axis I disorders (Eating Disorders and Chronic Pain Disorder). OCD patients showed significantly higher scores than the subjects of the other two groups in the areas of Dependence and Vulnerability schemes, belonging to domain of "Lack of autonomy and competence"; respectively indicative of the difficulty to deal autonomously with everyday life and of the feeling of being in constant danger, so much that it is necessary to be always alert. This result, totally consistent with the cognitive pattern earlier described, was shown to be in line with the results of a previous work by Atalay and collaborators (2008), which investigated the typical patterns in patients with OCD, obtaining a similar result. In this study (Atalay et al., 2008), scores at obsessive measure have been associated to the experience of frustration of 1) safe attachment, acceptance and care, 2) autonomy, 
competence sense of identity, 3) realistic limits and self-control, 4) free expression of needs and emotions and 5) spontaneity and playfulness core needs. This in turn may lead to the development of early maladaptive schemas such as 1) Emotional Deprivation, Defectiveness/Shame, Social Isolation, 2) Enmeshment/Undeveloped self, Vulnerability to harm, Failure, 3) Entitlement, 4) Subjugation, Approval-Seeking, and 5) Negativism/Pessimism, Unrelenting Standards. Two other schemas have been shown to significantly characterize the sample of OCD patients of Voderholzer and colleagues: the Abandonment schema and the Insufficient Self-Control schema, the latter belonging to the domain of "Hypervigilance and inhibition". The explanation given by the authors, that the core feeling of not being in control can be over-compensated by the development of obsessive symptomatology, in the form, for example, of compulsive control or mental rumination rituals, seems plausible. In comparison with the patients of the other two groups, the subjects with OCD also showed high scores to the "Vulnerable Child", "Angry Child", "Punitive Parent" and "Demanding Parent" modes. Already Gross and colleagues (2012), proposed a conceptualization of OCD in terms of modes, and identified the above mentioned modes as predominant. The obsessive symptomatology was explained by the authors in terms of compensatory mode, in the form of the Perfectionist Over-Controller mode and Avoidance mode, in the form of the Detached Protector mode.

A more recent work by Basile and colleagues (2017) has proposed to investigate patterns, modes and coping styles in a sample of OCD patients. Patients reported significantly higher scores in all early maladaptive schemas and dysfunctional modes compared to the healthy population. More in detail, the schemas with which a specific positive correlation with the severity of the obsessive symptomatology was found were the following: Emotional Deprivation, Defectiveness/Shame, Enmeshment, Unrelenting Standards, Punitiveness, Approval-Seeking. Regarding modes, instead, generally in line with what has already been proposed by Gross et al. (2012), the sample of patients was characterized by the prevalence of the following modes: Vulnerable Child, Undisciplined Child and Angry Child, as well as Demanding and Punitive Parent, the result of introjection of parental rules, which may explain the severity of the obsessive symptomatology. For a brief review of the works that have investigated schemas and modes in obsessive patients see Table 1.

Starting from findings described above, which laid the foundations for a conceptualization of the functioning of the OCD in terms of Schema Therapy, we have formulated a model of understanding of OCD arising from the integration of the explanation framework proposed by Mancini (2018) deriving from CBT with the contributions offered by Schema Therapy.

In the proposed model, the obsessive symptomatology is explained by the alternation of different modes.

In particular, the dynamics of the disorder is conceptualized as the presence of the following modes: 
Table 1. Main findings of previous studies investigating schema therapy related constructs (i.e., schemas and modes) in OCD populations.

\begin{tabular}{|c|c|c|}
\hline Authors & Early Maladaptive Schemas & Modes \\
\hline $\begin{array}{l}\text { Basile et al., } \\
\quad 2017\end{array}$ & $\begin{array}{l}\text { All schemas being higher in OCD vs healthy controls; } \\
\text { Correlations: association between OCD severity and } \\
\text { Failure, Punitiveness, Subjugation, Social Isolation }\end{array}$ & $\begin{array}{l}\text { Positive association } \\
\text { between OCD severity } \\
\text { and Punitive Parent }\end{array}$ \\
\hline $\begin{array}{l}\text { Kwak \& Lee, } \\
2015\end{array}$ & $\begin{array}{l}\text { Failure, Defectiveness/shame, Enmeshment, Social } \\
\text { Isolation (vs HC, PAD) }\end{array}$ & \\
\hline $\begin{array}{l}\text { Voderholzer et } \\
\text { al., } 2014\end{array}$ & $\begin{array}{l}\text { Failure, Punitiveness, Subjugation, Abandonment, } \\
\text { Defectiveness/shame, Insufficient Self-control, } \\
\text { Dependence, Vulnerability to harm (vs ED, CPD) }\end{array}$ & $\begin{array}{l}\text { Vulnerable and Angry } \\
\text { Child mode } \\
\text { Punitive and Demanding } \\
\text { parent }\end{array}$ \\
\hline Kim et al., 2014 & $\begin{array}{l}\text { All schemas being higher in OCD than in healthy } \\
\text { controls }\end{array}$ & \\
\hline $\begin{array}{l}\text { Atalay et al., } \\
\quad 2008\end{array}$ & $\begin{array}{l}\text { Failure, Punitiveness, Defectiveness/shame, } \\
\text { Unrelenting standard, Subjugation, Social Isolation, } \\
\text { Vulnerability to harm, Emotional deprivation, } \\
\text { Enmeshment, Entitlement, Approval-seeking }\end{array}$ & \\
\hline $\begin{array}{l}\text { Lochner et al., } \\
2005\end{array}$ & $\begin{array}{l}\text { Defectiveness/shame, Social Isolation, Subjugation, } \\
\text { Mistrust/abuse, Emotional inhibition }\end{array}$ & \\
\hline
\end{tabular}

- Vulnerable Child mode, guilty and fearful of disgust and of the relational consequences that this might entail (active in the first and second evaluation of the Mancini model);

- Angry Child mode (if present, active in the second evaluation);

- Demanding and Punitive mode (corresponding to the vulnerability that leads to the severity of the first and second evaluation);

- Avoidant Coping mode: Detached Protector and Self-Soother (if present, active in the second attempt to solve);

- Over-compensatory coping mode: Perfectionist Over-Controller (active in the first and second attempt to solve).

We will now resume the conceptualization of the case of Mark (Luppino et al., 2018), integrating it with the conceptualization according to the mode model, to describe the model proposed in this paper (see Figure 1). As you can see, (on the left) the Demanding and Punitive Parent, which represents the aspects of historical vulnerability, is present, in line with the information that recent research (Tenore et al., 2018) has provided on the type of parenting that obsessive patients have typically experienced. More specifically, this mode seems to reflect the pressure of unrealistic expectations on the part of the caregivers, associated with schemas such as Unrelenting Standards, Failure and Self-sacrifice; the punitive parent mode, on the other hand, represents rigid parenting rules concerning the possibility of being punished. This punishment is expressed as a threat to the continuity of the relationship, in case of error, and is generally associated with the schemas Subjugation, Mistrust/Abuse and Defectiveness.

Child modes represent those states of the patient in which negative emotions 


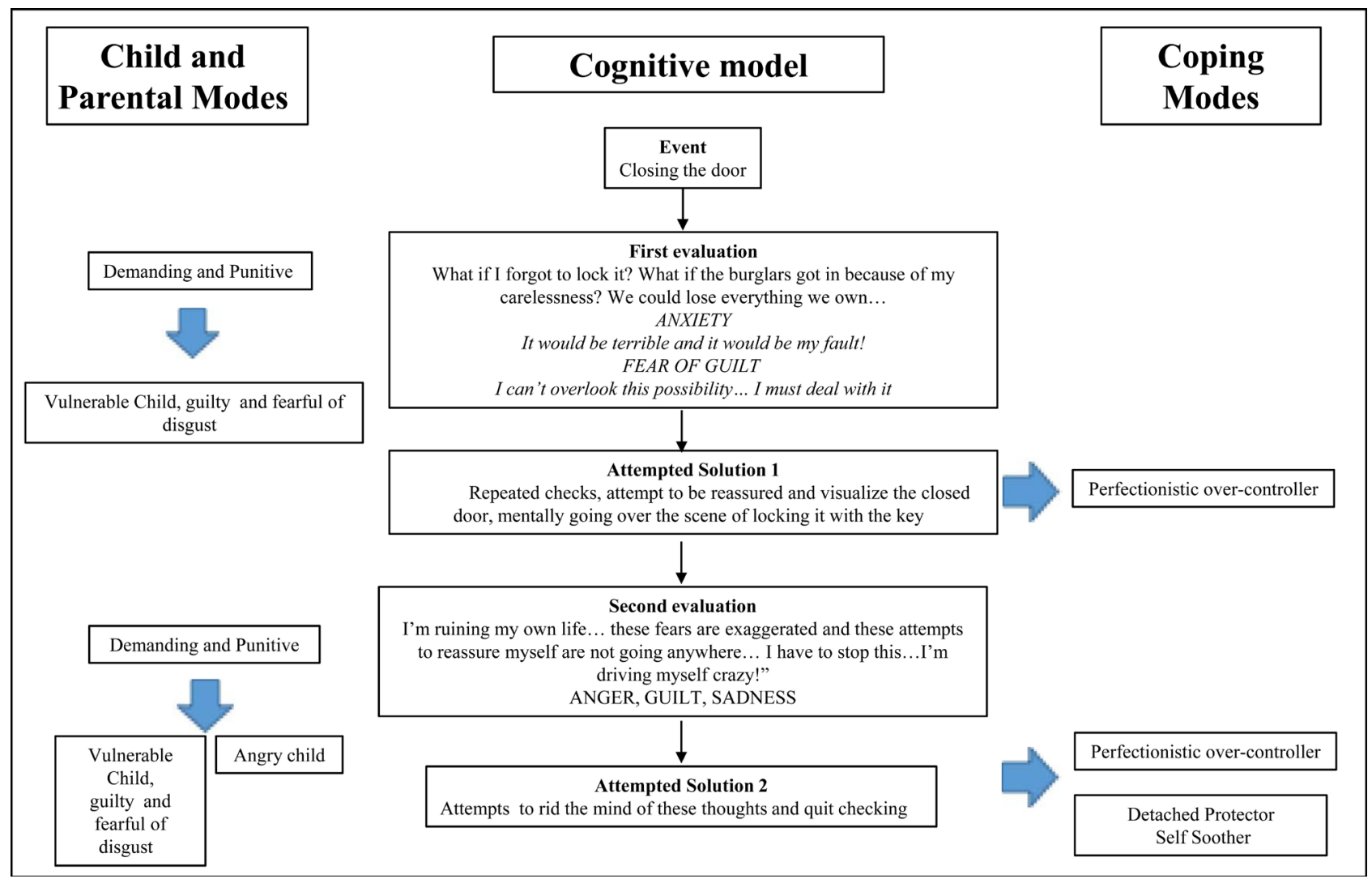

Figure 1. This figure describes Mark's case conceptualization, integrating his cognitive internal profile with the Schema Therapy mode model. 
strive continually to satisfy high performance expectations at the expense of pleasant activities and moments of emotional sharing. An alternative way to manage pain is the Detached Mode which allows subjects to "not feel" discomfort, to distance themselves from the painful emotional contents, protecting themselves by means of distraction, social isolation, avoidance of situations capable of triggering them (Detached Protector mode) or through self-gratification (Detached Self-Soother mode). Consistent with the conceptualization here presented, the rationale of the intervention on individual modes will be illustrated below with a view to acceptance of the feared threat; the third paper of this trilogy, on the other hand, will provide more points to be discussed, clarifying the choice and use of the various techniques in more detail. We will not focus on the specificity of the therapeutic relationship, in that we suggest to maintain the general approach proposed by Schema Therapy.

\section{Rationale of the Intervention}

As stated in the previous article by Luppino et al. (2018), to gain a more complete understanding of a disorder it is fundamental to understand the recursive processes that maintain the current symptomatology. However, it is also necessary to understand the conditions that have made the patient vulnerable to the development of OCD. It is about understanding the experiences, especially of a relational kind, that have made the patient more sensitive to the themes of guilt, in particular deontological guilt, and of disgust. The conceptualization of the case involves, therefore, operating on two levels, inextricably connected, a present one, the patient's here and now, and one linked to past sensitizing experiences. What connects these two levels is the set of dysfunctional beliefs and maladaptive ways of coping with them. In line with a global therapeutic approach of OCD, Mancini (2018) identifies two strategic therapeutic objectives, the first aimed at interrupting recursive processes, the second aimed at reducing the patient's sensitivity towards guilt or the experience of disgust.

As has been amply demonstrated (Wegner et al., 1987) attempts to contrast obsessive contents and emotions associated with these involve a paradoxical increase in the thoughts themselves and a greater urgency to implement compulsions. To interrupt the recursive processes that maintain and exacerbate the obsessive symptomatology, the patient must abandon or at least reduce the attempts to neutralize the threat connected to the content of the obsessions. The difficulty that patients encounter with the prospect of abandoning attempts to neutralize (compulsions) are linked to both intolerance of the emotional state the threat produces, but above all to the prospect of feeling guilty because they have not done everything that was in their power to avoid the harm related to the threat. But when can a person say that he or she has really done everything that was possible? The answer to this question is variable and it depends on which mode we are interacting with. Obviously the patient using a Healthy Adult mode realizes that absolute certainty is not achievable and that everyone, 
consciously or not, day after day, decides to accept a certain degree of risk. Let's put ourselves in the patient's position, in the Perfectionistic Over-Controller mode. If we think about it, three hours of washing are no closer to "everything in their power" than two hours, so why not extend the washing routine to four hours?

The attempt to attain the condition of having done everything possible reinforces threatening thoughts and therefore leads to perceive the occurrence of an event as being more likely. The purpose of the work with obsessive patients is not to reassure them of the possibility that the feared outcome will not take place. Indeed, some data show that entering into a dialectical kind of dialogue with an obsessive patient is not only useless, but counterproductive (van den Hout \& Giele, 2018). In fact, OCD patients are not interested in the probability with which an event might occur, rather they are interested in avoiding the possibility itself. Reasoning with the patient about the occurrence of a threat can cause this thought to become even more mentally intrusive. According to the model (Mancini \& Barcaccia, 2004; Mancini \& Gragnani, 2005; Mancini, 2018), the aim of the work is to replace the effort to attain absolute certainty (carried out by means of avoidance, requests for reassurance and other forms of threat neutralization) with an approach of acceptance of the possibility that one may be guilty, or that one may come into contact with disgusting substances, or be judged as being disgusting, which entails the risk of being rejected. This objective is achieved with work on the recursive processes in place and with a work that allows the patient to grasp the sense and the historical reasons for his or her sensitivity to guilt, and then reduce it: these are obviously interventions aimed at improving the skills of the Healthy Adult Mode, which are, however, mainly aimed specifically at managing and/or replacing dysfunctional modes.

The mode work with obsessive patients has several purposes:

a) Respond to the emotional needs of the Vulnerable Child mode, the Guilty Child, afraid of disgust and of the relational consequences that this could entail;

b) Reduce the pervasiveness and severity of the Demanding and Punitive mode;

c) Replace the strategies of the Perfectionistic Over-Controller with modalities of acceptance of the risk connected to the feared threat;

d) Establish rules for a proper management of anger, in case one is dealing with an Angry Child mode caused by criticism or by the costs of the disorder (Second evaluation, see Luppino et al., 2018);

e) Modify Avoidance Coping modes (detached protector and self soother) that prevent access to the vulnerable child mode and therefore to the satisfaction of basic emotional needs;

f) Strengthen the Healthy Adult mode, to allow the patient to accept a functional degree of risk of being guilty, favoring the component of acceptance of the healthy adult mode.

We will now analyze in detail the therapeutic rationale for the reduction of 
dysfunctional modes and the strengthening of functional modes.

1) Respond to the emotional needs of the Child Mode who is guilty and afraid of disgust:

In the wake of clinical observation and research data describing sensitizing experiences of fear of guilt and loathing (Barcaccia et al., 2015; Tenore \& Basile, 2018), the clinical work is aimed at responding to the emotional needs represented by the guilt-driven and fearful child mode. In particular, the work must favour a restructuring of the expectation of rejection in case of error. The belief that making a mistake is a catastrophic event must be replaced by the perception of having the same right to make mistakes as others, and that this will not result in dramatic relational consequences such as a break in the relationship. It is very important to pay attention so that the intervention is aimed at a decrease in the sensitivity to guilt, which does not automatically translate into blaming someone else. This could indeed generate feelings of anger, which, however legitimate, do not direct the focus on the acceptance of the possibility of being guilty, but only move the attribution of guilt on someone else, not entailing, therefore, a change in sensitivity to guilt. The blaming attitude, which is expressed in the search for the person responsible and in blaming this person, is typical of obsessive families (Tenore \& Basile, 2018). Such search is, in some cases, motivated by an attempt to evade personal responsibilities, since the attribution of guilt to another person entails a feeling of innocence (Castelfranchi, Mancini, \& Miceli, 2002).

Less numerous studies have carried out a more in depth analysis of the ways in which a person can become sensitized to the issue of disgust (Tomkins, 1963; Rozin \& Fallon, 1987; Rozin et al., 2000; Wicker et al., 2003). Although there are no studies or formulations in this regard, parental modelling with respect to factors eliciting disgust could be the basis for the formation of Punitive and Demanding modes, especially when these factors have a moral nature. Moral disgust, compared to physical disgust, presents more relational connotations (Tybur et al., 2012), and perceiving oneself as morally disgusting may be related to a threat to the continuity of a relationship. As stated in the previous work (Luppino et al., 2018) there is a partial overlap between deontological guilt and moral disgust. Although there are no studies that have broadened the relationship between schemas and the emotion of disgust, it makes sense to think that this emotion is the expression of the activation of the schemas of Vulnerability, of Unrelenting Standards or of Punishment. The patient in the Vulnerable Child mode perceives that it is intolerable to enter into contact with, or have the doubt of having come into contact with a disgusting substance. In addition to implying an idea of danger, coming into contact with disgusting substances implies the idea that one may acquire characteristics that belong to these substances. The eliciting factors of disgust are associated with immorality and determine a feeling of debasement; the fear they cause depends on the association of dirt with the feeling of being morally deplorable, which is similar to the effect of guilt. The purpose of the 
interventions on disgust is, also in this case, not to reassure the patient in the Child mode, so stressing the fact that an event is harmless, but to work on acceptance, even though the patient might perceive him of herself as dirty/immoral. For an example of how to achieve this therapeutic goal (see Basile et al., 2018).

2) Reduce the pervasiveness and severity of the Demanding and Punitive mode

The presence of clinical perfectionism and particularly strict moral standards in OCD is stressed by numerous studies (Frost \& Steketee, 1997; Doron et al., 2007; Franklin et al., 2009). Going back to the clinical case of Mark, when the patient is in this mode, he does not tolerate the slightest doubt concerning the possibility of being homosexual, or the possibility of being able to cause harm. In this mode, the prospect of an error is associated with a very severe punishment. Mark, in fact, imagines that the consequence is rejection by all the people dear to him. The experience of a peripheral father, who, however, complies with his wife's standards in case of error, causes Mark to form the perception of a world that is ready to cut him out, as when for days at home no one used to speak to him because he had not complied with the rules set by his parents.

The patient's experience with the contents of an obsession is that of undergoing a trial in a very strict courtroom. This mode must be banned from patients' experience, so they may free themselves of suffocating and inhibiting criticism, which prevents them from being able to take advantage of what they have built. Critical internalization must be replaced by the ability to motivate oneself in a healthy and realistic way, with realistic standards and expectations. It is important to remember that this is an internalized mode, something that is learned through imitation/modelling (see Berne, 1961). There may be circumstances in which the proposed standards do not correspond to the motivations of patients, and in this case it is advisable to work with patients so they may define their own goals.

Accepting the possibility of being guilty and having a compassionate attitude towards oneself, in the prospect that it is possible to make mistakes, are the most powerful weapons to counteract the Critical Parent mode. It is a form of acceptance in which personal value is disconnected from the fulfillment of perfectionist tasks. A work aimed at reducing the severity of moral standards and performance is necessary to allow patients to reduce the frequency and the inflexibility with which they judge themselves and their actions. The work on perfectionism also entails the modification of the dichotomous approach "all or nothing". This modification implies understanding and tolerating imperfection, integrating the latter into a unity made up of pros and cons.

3) Replace the strategies of the Perfectionistic Over-Controller with modalities of acceptance of the risk connected to the feared threat

The activation of the Perfectionistic Over-Controller mode represents the survival strategy with which patients defends themselves from the severity of the parent mode, which threatens the patient in the child mode with the prospect of severe punishment, and of the demanding parent that sets very high standards. 
Like all dysfunctional coping modes and like all perfectionist strategies, the Perfectionistic Over-Controller mode, in order to respond to the ever-increasing demands of the parent mode, engages in activities that require more and more energy and time. Increasing demands, which do not however determine a state of satisfaction, correspond to higher costs and lead to the deterioration of the quality of life of the patient. The rationale of intervention on the Perfectionistic Over-Controller mode is the abandonment of neutralization strategies. Such abandonment involves accepting the experience of fear of being guilty, of being contaminated or disgusting for a longer time than the patient usually manages to tolerate. Patients will therefore have to consciously abstain from the immediate (but short lasting) feeling of relief that follows the implementation of compulsions. At this stage, it is a question of working together with the patient to promote, in a Healthy Adult mode, the development of a state of conscious acceptance, a mode that we can call "accepting", in which the patient, guided and supported by the therapist, chooses to tolerate the unpleasant emotions that accompany the abstention from compulsion. The replacement of attempts at neutralization involves an uncomfortable experience and an urgency to cope with it. A non-judgmental attitude and the recognition that it is a state, by definition transitory, guides the patient through negative emotions.

4) When treating an Angry Child mode, establish rules for a proper management of anger

The inflexibility of strict standards can generate fear in the Child mode, but also anger when the child is blamed. If in the Vulnerable Child mode, the patient can experience strong feelings of fear, disgust or general discomfort, for the activation of the same patterns he may feel anger when the need for security and acceptance is frustrated. The expression of anger in itself does not constitute any problematic modality, but a particularly aggressive expression, in addition to being dysfunctional from a relational point of view, reactivates the critical parent. Following expressions of anger caused by the rituals, or the criticisms coming from people around, or because of autonomous acknowledgment of the costs of the disorder, Mark experiences an intense emotion of guilt and fear of non-acceptance, whereby his internal dialogue is characterized by the injurious and critical tones of the Parent Mode, that sets very strict ethical standards and punishes him by threatening to break the relationship if these are disregarded. As we can imagine, at this point the circle starts again. In order not to feel the tension of the critical parent's accusations against the Child mode, the Perfectionistic Over-Controller mode is activated, which aims to reach the parent's unrealistic standards, and does it through rumination, tests to assess virility and requests for reassurance.

The objective of the work done with a patient in an Angry Child mode is to define clear limits inside which the patient can express frustration, differentiating the legitimate emotion from its wrong expression. Furthermore, it is necessary to differentiate the present anger from the anger originating in the past. 
Present criticisms might trigger and activate schemas, and therefore the memory component, leading to a sort of overlap between present and past.

The patient must be helped to communicate his or her reasons in an adult and assertive way, and to express anger in a healthy way.

5) Modify Avoidance Coping Modes (i.e., Detached Protector and Self-Soother) that prevent access to the vulnerable child mode and therefore to the satisfaction of basic emotional needs

There are different strategies of emotional regulation that a person can put in place to manage negative emotions. These strategies are not necessarily dysfunctional, they become so when they become rigid, pervasive or exclusive and especially when they do not permit the satisfaction of basic emotional needs.

It is important, in the conceptualization of obsessive patients, to differentiate between avoidance strategies (Detached Protector and Self Soother) and overcompensation strategies (Perfectionistic Over-Controller). In the first case, strategies are used to avoid contact with negative emotions, while in the latter strategies are aimed at neutralizing the risk that a negative event might occur. Clearly also in this second case the experience is characterized by a negative emotion, calmed by the compulsions temporarily, but whose main objective is to reduce of the risk of the feared threat occurring.

Avoidance modes have the function of keeping negative emotions at bay, but as already stated, they hinder the satisfaction of primary needs. In the case of patients in a Detached Protector Mode, they are emotionally detached from others, experience boredom or a sense of emptiness, a sort of emotional void. Detached Self Soothers, on the other hand, regulate emotions by engaging in activities, which can somehow calm them, stimulate them or distract them from their own stimuli. Although they can be carried out in an additive or compulsive way, these are not compulsions. In Mark's case, for example, masturbatory activity can be carried out with the aim of neutralizing the hypothesis of being homosexual, but when the patient is in this mode, masturbation is aimed at reducing negative emotional states. In some circumstances, cleaning can perform the same function; patients may perform this activity not to reduce a threat, but to anesthetize their emotional states. It is easy to understand how, although these are not compulsions, these types of emotional regulation strategies are constituted as a maintenance factor for the disorder.

The aim of the work on Avoidance Coping modes is to substitute them with cognitive, behavioral and relational modalities that can help the patient contact emotional needs and to satisfy them in a functional way.

6) Strengthen the Healthy Adult Mode, to allow the patient to accept a functional degree of risk of being guilty. The therapy is entirely aimed at enhancing the skills of this patient mode. In practical terms, it is about making sure that the patient spends as much time as possible in this adaptive mode, returning to it as quickly as possible every time there a slip into dysfunctional modes. According to Roediger (2015), the process of strengthening the Healthy Adult mode entails the exercise and the structuring of three functions (Table 2). 
Table 2. Adapted from Roediger (2015).

\begin{tabular}{|c|c|c|}
\hline \multicolumn{3}{|c|}{ Functions of the Healthy Adult Mode } \\
\hline $\begin{array}{l}\text { Pay attention and be aware that the } \\
\text { system is not working, turn one's } \\
\text { attention elsewhere (disidentification) }\end{array}$ & $\begin{array}{l}\text { Reassess the situation from a } \\
\text { greater distance and choose a } \\
\text { better system (change of } \\
\text { perspective) }\end{array}$ & $\begin{array}{l}\text { Change pattern (breaking } \\
\text { behavioural patterns) } \\
\text { voluntarily and also with } \\
\text { effort }\end{array}$ \\
\hline
\end{tabular}

These functions of the healthy adult mode, in the treatment of obsessive patients must be developed paying attention to some peculiarities.

1) Pay attention and be aware that the system is not working, turn one's attention elsewhere (disidentification); the cost of the disorder for obsessive patients can be particularly high. Emotional suffering and the consequences on the relational and professional level are in many cases particularly serious. This is often the reason for the request for treatment. However, patients can ask for help, and at the same time retain the idea they must protect themselves from the possibility of being guilty or from coming into contact with disgusting substances. In a sense, therapy can be interpreted, at the beginning, as a way to reduce the costs of the disorder, keeping the "anti-goal" active (not being guilty or disgusting and not contaminating oneself with disgusting substances). It is thus necessary to form an alliance with patients and show them that the system does not work, not only because compulsions are costly, but especially because they cannot change this sense of danger, and that therefore the only way out is to accept the possibility of being guilty of this. Through the process of disidentifiation it is also possible to increase the latency between the onset of the obsession and the impulse to implement a compulsion.

2) Reassess the situation from a greater cognitive or emotional distance and choose a better system (change of perspective); Central to this function of the Healthy Adult mode is the transition from the need, the opportunity and duty to perform compulsions to avoid the possibility of being guilty or disgusting, or of coming into contact with disgusting substances, to acceptance of these possibilities. For patients it is crucial to recognize that they can abstain from doing what their critical part orders them to do, threatening catastrophic outcomes. As reported by Mancini and collaborators (Mancini \& Gragnani, 2005; Mancini \& Perdighe, 2011), human beings invest in the pursuit of a goal proportionally to how much they believe it is in their power to achieve it, and that it is advantageous and proper to do so. To give up the idea that guilt can be prevented and accept a "possible compromise" provides for a revision of the beliefs in this same objective. Patients thus reevaluate the possibility and the plausibility of this objective-not to become responsible for any type of guilt, to prevent this possibility-and the beliefs about the catastrophic consequences in case of error.

3) Changing the pattern (breaking behavioural patterns) voluntarily and also with effort. In the initial stages washing, avoidance, control or any other type of neutralization attempt constitute the behavioral pattern typical of the obsessive patient, and the central factor in the maintenance of the disorder. The behavioral 
change that entails the decision to follow the procedures of Exposure through Response Prevention, requires a lot of effort but is central in the change of patients who disinvest from the aim of being perfect in the eyes of the Demanding and Punitive Mode.

\section{Conclusion}

Within the conceptual framework offered by Cognitive model for the understanding of OCD, a reading in terms of schemas and modes can bring an important contribution to the understanding of the factors of historical vulnerability underlying the etiology of the disorder, and of the recursive mechanisms which result in the choice of poorly functional behavior, not able to contain the problem and actually responsible for its maintenance.

A greater awareness of the patients' core patterns may represent additional information for the therapist, information that is useful for a more accurate planning of the intervention project. The integration of the Cognitive treatment model with the techniques offered by Schema Therapy may, in our opinion, represent a particularly useful proposal for all those cases of severe or chronic OCD, as well as for all those patients with a traumatic history or with important personality traits behind them.

In this paper the rationale of the intervention that has been proposed results from a conceptualization of OCD, which brings together the CT models (Mancini, 2018) and the ST model described by Basile et al. (2017). Strategic objectives have been set for each individual mode that describes the obsessive patient's experience, in order to pursue the general goal of accepting the risk of being guilty or of coming into contact with disgusting substances. In the following work (Basile et al., 2018) procedures and intervention techniques will be described to pursue the rationale proposed here.

\section{Conflicts of Interest}

The authors declare no conflicts of interest regarding the publication of this paper.

\section{References}

Abramowitz, J. S., Franklin, M. E., Schwartz, S. A., \& Furr, J. M. (2003). Symptom Presentation and Outcome of Cognitive-Behavioral Therapy for Obsessive Compulsive Disorder. Journal of Consulting and Clinical Psychology, 71, 1049-1057. https://doi.org/10.1037/0022-006X.71.6.1049

Arntz, A. (2012). Schema Therapy for Cluster-C Personality Disorders. In M. van Vreeswijk, J. Broersen, \& M. Nadort (Eds.), The Wiley-Blacllwell Handbook, of Schema Therapy: Theory, Research, and Practice. Hoboken: John Wiley \& Sons, Ltd. https://doi.org/10.1002/9781119962830.ch30

Atalay, H., Atalay, F., Karahan, D., \& Caliskan, M. (2008). Early Maladaptive Schemas Activated in Patients with Obsessive Compulsive Disorder: A Cross-Sectional Study. International Journal of Psychiatry in Clinical Practice, 12, 268-279.

https://doi.org/10.1080/13651500802095004 
Barcaccia, B., Tenore, K., \& Mancini, F. (2015). Early Childhood Experiences Shaping Vulnerability to Obsessive-Compulsive Disorder. Clinical Neuropsychiatry, 12, 141-147.

Basile, B., Fadda, S., De Sanctis, B., Saliani, A. M., Perdighe, C., Luppino, O. I., Tenore, K., \& Mancini, F. (2018). Early Life Experiences in OCD and Other Disorders: A Retrospective Observational Study Using Imagery with Re-Scripting Characterize OCD, But Not Other Disorders. Clinical Neuropsychiatry. [In Press]

Basile, B., Luppino, O. I., Mancini, F., \& Tenore, K. (2018). An Integration of Schema and Cognitive Therapy in OCD Treatment (Part III): Experiential Techniques and Cognitive Based Interventions. Psychology, 9, 2296-2311.

https://doi.org/10.4236/psych.2018.99130.

Basile, B., Tenore, K., Luppino, O. I., \& Mancini, F. (2017). Schema Therapy Mode Model Applied to OCD. Clinical Neuropsychiatry, 14, 407-414.

Behary, W. T. (2009). Disarming the Narcissist: Surviving and Thriving with the Self-Absorbed. Oakland: New Harbinger Publications.

Berne, E. (1961). Transactional Analysis in Psychotherapy: The Classic Handbook to Its Principles. London: Condor.

Castelfranchi, C., Mancini, F., \& Miceli, M. (2002). Fondamenti di cognitivismo clinico. Torino: Bollati Boringhieri.

Consentino, T., D’Olimpio, F., Perdighe, C., Romano, G., Saliani, A. N., \& Mancini, F. (2012). Acceptance of Being Guilty in the Treatment of Obsessive-Compulsive Disorder. Psicoterapia Cognitiva e Comportamentale, 39-56.

Cosentino, T., \& Mancini, F. (2012). “Do I Love Her or Not?!” Intervention on Fear of Being Despised: An Obsessive-Compulsive Disorder Case Presentation. Psicoterapia Cognitiva e Comportamentale, 18, 199-213.

Doron, G., Kyrios, M., \& Moulding, R. (2007). Sensitive Domains of Self-Concept in Obsessive-Compulsive Disorder (OCD): Further Evidence for a Multidimensional Model of OCD. Journal of Anxiety Disorders, 21, 433-444. https://doi.org/10.1016/j.janxdis.2006.05.008

Franklin, S. A., McNally, R. J., \& Riemann, B. C. (2009). Moral Reasoning in Obsessive-Compulsive Disorder. Journal of Anxiety Disorders, 23, 575-577. https://doi.org/10.1016/j.janxdis.2008.11.005

Frost, R. O., \& Steketee, G. (1997). Perfectionism in Obsessive-Compulsive Disorder Patients. Behaviour Research and Therapy, 35, 291-296. https://doi.org/10.1016/S0005-7967(96)00108-8

Gross, E. N., Stelzer, N., \& Jacob, G. (2012). Treating OCD with the Schema Mode Model. In M. van Vreeswijk, J. Broersen, \& M. Nadort (Eds.), The Wiley-Blackwell Handbook of Schema Therapy: Theory, Research, and Practice. Hoboken: John Wiley \& Sons, Ltd. https://doi.org/10.1002/9781119962830.ch11

Kellogg, S. H., \& Young, J. E. (2006). Schema Therapy for Borderline Personality Disorder. Journal of Clinical Psychology, 62, 445-458. https://doi.org/10.1002/jclp.20240

Kim, J. E., Lee, S. W., \& Lee, S. J. (2014). Relationship between Early Maladaptive Schemas and Symptom Dimensions in Patients with Obsessive-Compulsive Disorder. Psychiatry Research, 215, 134-140. https://doi.org/10.1016/j.psychres.2013.07.036

Kwak, K. H., \& Lee, S. J. (2015). A Comparative Study of Early Maladaptive Schemas in Obsessive-Compulsive Disorder and Panic Disorder. Psychiatry Research, 230, 757-762. https://doi.org/10.1016/j.psychres.2015.11.015

Lochner, C., Seedat, S., Du Toit, P. L., Nel, D. G., Niehaus, D. J., Sandler, R., \& Stein, D. J. (2005). Obsessive-Compulsive Disorder and Trichotillomania: A Phenomenological 
Comparison. BMC Psychiatry, 5, 2.

Luppino, O. I., Tenore, K., Mancini, F., \& Basile, B. (2018). An Integration of Schema and Cognitive Therapy in OCD Treatment (Part I): Goals and Beliefs of the Obsessive Mind. Psychology, 9, 2261-2277. https://doi.org/10.4236/psych.2018.99131

Mancini, F. (2018). The Obsessive Mind. Abingdon-on-Thames: Routledge.

Mancini, F., \& Barcaccia, B. (2004) The Importance of Acceptance in Obsessive-Compulsive Disorder. Munich: Ludwig-Maximilians University.

Mancini, F., \& Gangemi, A. (2004) Fear of Guilt from Behaving Irresponsibly in Obsessive-Compulsive Disorder. Journal of Behavior Therapy and Experimental Psychiatry, 35, 109-120. https://doi.org/10.1016/j.jbtep.2004.04.003

Mancini, F., \& Gragnani, A. (2005) L'esposizione con prevenzione della risposta come pratica dell'accettazione. Cognitivismo Clinico, 2, 38-58.

Mancini, F., \& Perdighe, C. (2011) Perché si soffre? Il ruolo della non accettazione nella genesi e nel mantenimento della sofferenza emotiva. Cognitivismo Clinico, 9, 95-115.

Perdighe, C., \& Mancini, F. (2012). Dall'investimento alla rinuncia: Favorire l'accettazione in psicoterapia. Cognitivismo Clinico, 9, 116-134.

Renner, F., Arntz, A., Leeuw, I., \& Huibers, M. (2013). Treatment for Chronic Depression Using Schema Therapy. Clinical Psychology: Science and Practice, 20, 166-180. https://doi.org/10.1111/cpsp.12032

Roediger, E. (2015). Why Are Mindfulness and Acceptance Central Elements for Therapeutic Change in Schema Therapy Too? An Integrative Prospective. In: M. van Vreeswijk, J. Broersen, \& M. Nadort (Eds.), Handbook of Schema Therapy, Theory, Research and Practice (pp. 239-248). New York: Wiley Blackwell.

Rozin, P., \& Fallon, A. E. (1987). A Perspective on Disgust. Psychological Review, 94, 23-41. https://doi.org/10.1037/0033-295X.94.1.23

Rozin, P., Haidt, J., \& McCauley, C. R. (2000). Disgust. In M. Lewis, \& J. Haviland-Jones (Eds.), Handbook of Emotions (2n ed., pp. 673-653). New York: Guilford Press.

Rufer, M., Fricke, S., Moritz, S., Kloss, M., \& Hand, L. (2006). Symptom Dimensions in Obsessive Compulsive Disorder: Prediction of Cognitive Behavioural Therapy Outcome. Acta Psychiatrica Scandinavica, 113, 4404-4446. https://doi.org/10.1111/j.1600-0447.2005.00682.x

Tenore, K., \& Basile, B. (2018). The Hystorical Vulnerability in OCD. In F. Mancini (Ed.), The Obsessive Mind. Abingdon-on-Thames: Routledge.

Tenore, K., \& Serrani, F. M. (2013). La Schema Therapy. Caratteristiche Distintive. Milano: Franco Angeli.

Tenore, K., Basile, B., Cosentino, T., De Sanctis, B., Fadda, S., Gragnani, A., Luppino, O. I., Perdighe, C., Romano, G., Saliani, A. M., \& Mancini, F. (2018). Efficacy of Imagery with Rescripting in Treating OCD: A Single Case Series Experimental Design (Preliminary Results).

Thiel, N., Jacob, G. A., Tuschen-Cafer, B., Herbst, N., Kuilzm, A. K., Hertenstein, E. et al. (2016). Schema Therapy Augmented Exposure and Response Prevention in Patients with Obsessive-Compulsive Disorder: Feasibility and Efficacy of a Pilot Study. Journal of Behavior Therapy and Experimental Psychiatry, 52, 59-67. https://doi.org/10.1016/j.jbtep.2016.03.006

Tolin, D. F., Maltby, N., Diefenbach, G., Hannan, S. E., \& Worhunsky, P. (2004). Cognitive Behavioural Therapy for Medication Nonresponders with Obsessive Compulsive Disorder: A Wait List Controlled Open Trial. Journal of Clinical Psychiatry, 65, 
922-931. https://doi.org/10.4088/JCP.v65n0708

Tomkins, S. (1963). Affect/Imagery/Consciousness, Vol. 2: The Negative Affects. New York: Springer.

Tybur, J. M., Lieberman, D., Kurzban, R., \& DeScioli, P. (2012). Disgust: Evolved Function and Structure. Psychological Review, 120, 65-84.

van den Hout, M., \& Giele, K. (2018). Why Challenging the Content of Obsessive Concerns Can Be Anti-Therapeutic: Experiences from Supervision and Experiment.

Veale, D., Page, N., Woodward, E., \& Salkovskis, P. (2015). Imagery Rescripting for Obsessive Compulsive Disorder: A Single Case Experimental Design in 12 Cases. Journal of Behavior Therapy and Experimental Psychiatry, 49, 230-236.

https://doi.org/10.1016/j.jbtep.2015.03.003

Voderholzer, U., Schwartz, C., Thiel, N., Kuelz, A. K., Hartmann, A., Scheidt, C. E. et al. (2014). A Comparison of Schemas, Schema Modes and Childhood Traumas in Obsessive-Compulsive Disorder, Chronic Pain Disorder and Eating Disorders. Psychopathology, 47, 24-31. https://doi.org/10.1159/000348484

Vos, S. P. F., Huibers, M. J. H., \& Arntz, A. (2012). Experimental Investigation of Targeting Responsibility versus Danger in Cognitive Therapy of Obsessive-Compulsive Disorder. Depression and Anxiety, 29, 629-637. https://doi.org/10.1002/da.21915

Wegner, D. M., Schneider, D. J., Carter, S. R., \& White, T. L. (1987). Paradoxical Effects of Thought Suppression. Journal of Personality and Social Psychology, 53, 5-13. https://doi.org/10.1037/0022-3514.53.1.5

Wicker, B., Keysers, C., Plailly, J., Royet, J. P., Gallese, V., \& Rizzolatti, G. (2003). Both of Us Disgusted in My Insula: The Common Neural Basis of Seeing and Feeling Disgust. Neuron, 40, 655-664. https://doi.org/10.1016/S0896-6273(03)00679-2

Young, J. E., Klosko, J. S., \& Weishaar, M. E. (2003). Schema Therapy: A Practitioner's Guide. New York: Guilford Press. 